\section{Fractures of the Proximal Tibia Associated with Longterm Use of Methotrexate: 3 Case Reports and a Review of Literature}

\section{To the Editor:}

There are several therapeutic options for which methotrexate (MTX) represents an excellent choice as systemic therapy for mild to severe psoriasis, psoriatic arthritis, and rheumatoid arthritis (RA). MTX is a folic acid antagonist, inhibiting dihydrofolate reductase, an enzyme that converts dihydrofolate to tetrahydrofolate. Impedance of this reaction interferes with purine synthesis and DNA biosynthesis, resulting in dysfunction of DNA replication, followed by cell death ${ }^{1}$. MTX is commonly used in high doses for the treatment of malignancies, and in lower doses (up to $30 \mathrm{mg}$ once weekly) for autoimmune diseases such as RA and psoriasis ${ }^{2}$.

MTX osteopathy was first described in children with leukemia who were treated with high doses of MTX and was characterized by bone pain, localized osteopenia, and sometimes even microfractures ${ }^{1,3}$. Some studies suggest also that longterm use of low-dose MTX can aggravate the development of osteopenia and stress fractures ${ }^{1,4,5}$.
Here we describe 3 patients with proximal tibia fractures treated with a low to intermediate dose of MTX.

Case 1. A 51-year-old white woman presented with increasing pain in both knees. Her medical history included a left ankle fracture, a right meniscectomy, and enthesopathy based on psoriasis. Her body weight was $80 \mathrm{~kg}$ with a height of $165 \mathrm{~cm}$. She denied any severe trauma preceding her complaints. Her family history was negative for rheumatism and associated symptoms and she has been treated for psoriasis with MTX (maximum dosage $15 \mathrm{mg}$ once weekly) for 12 years. Further medication included pantoprazole (20 mg once daily) and mianserin ( $30 \mathrm{mg}$ once daily). Folic acid was not prescribed, nor was preventive medication for osteoporosis such as calcium or biphosphonates.

On physical examination there were no signs of arthritis. Both knees had crepitus with flexion and extension. The left knee especially was very painful on examination. Radiographs of both knees showed a transverse mainly consolidated medial tibia fracture with periostal callus formation that was more distinct on the left side than on the right (Figure 1). Magnetic resonance imaging (MRI) with gadolinium showed a fracture of the left proximal tibia plateau (coronal T1-weighted sequence; Figure 2).

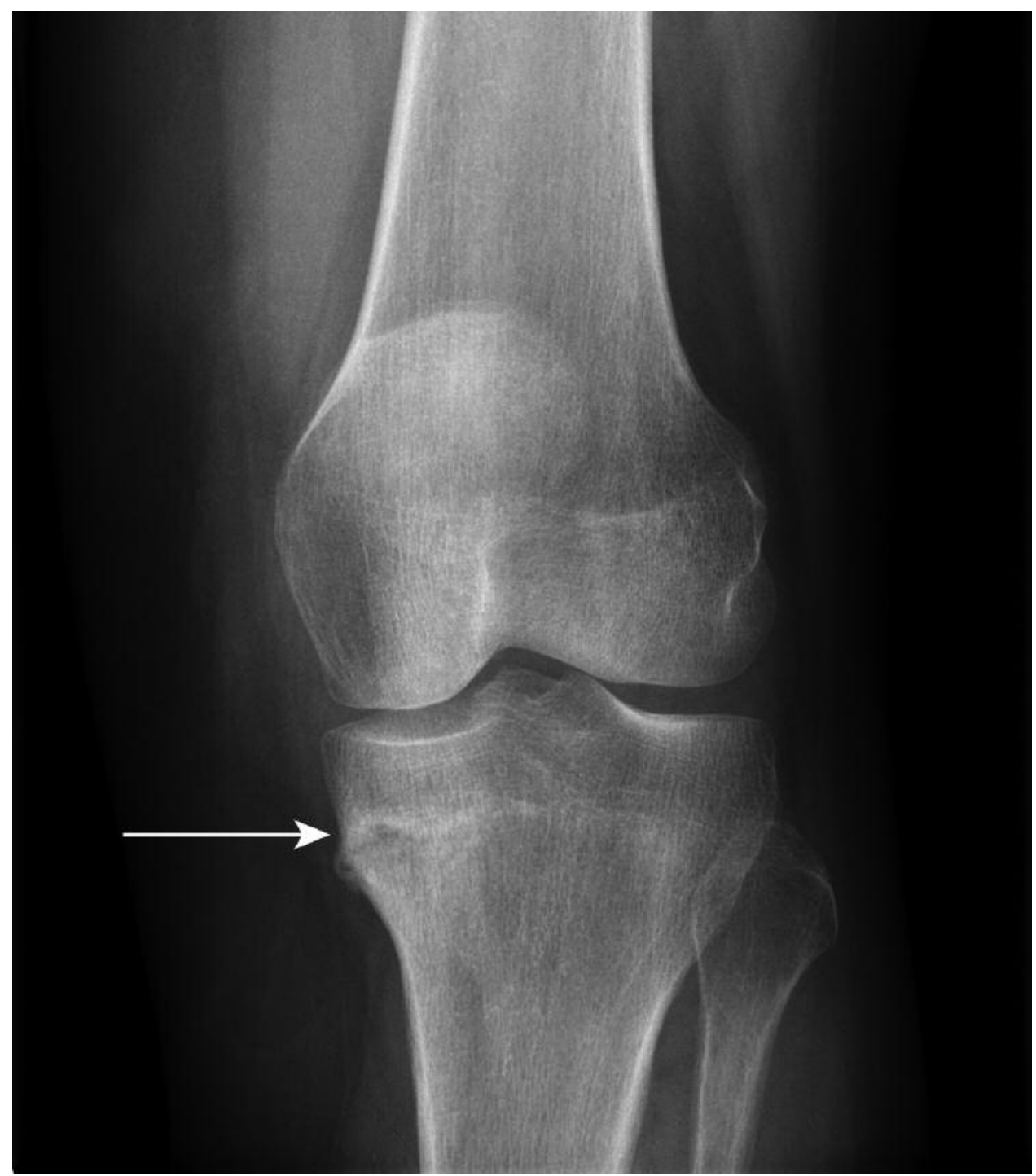

Figure 1. Anteroposterior radiograph of the left knee shows a transverse fracture of the proximal tibial metaphysis with fracture margin sclerosis (arrow). 


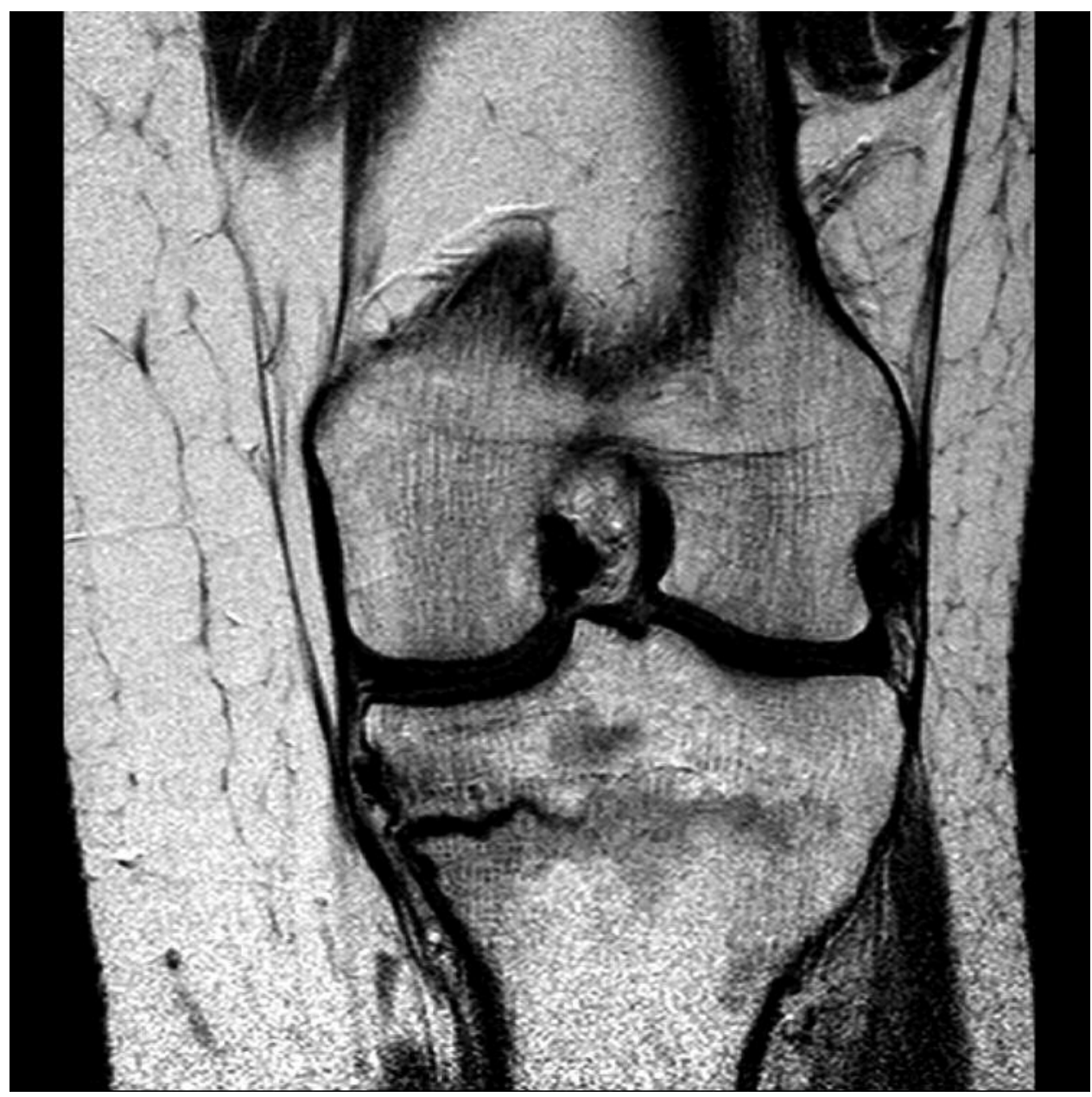

Figure 2. Coronal contrast material-enhanced T1-weighted magnetic resonance image shows a hypointense transverse fracture of cancellous and cortical bone of the proximal tibial metaphysis. There is associated bone marrow and periosteal edema.

Laboratory tests showed an increased alkaline phosphatase of $190 \mathrm{U} / 1$ corresponding with increased bone turnover often seen in a fracture. Other laboratory tests were normal. Dual energy x-ray absorptiometry (DEXA) showed osteopenia. The results of the bone mineral density (BMD) of the lumbar were a $\mathrm{T}$ score of -1.1 and -0.8 of the total hip. A bone biopsy of the left tibia plateau was taken. The histological findings showed signs of increased bone turnover and fibrosis of the bone marrow without signs of osteoporosis or osteonecrosis. There were no signs of a malignancy. Treatment with MTX was discontinued and the patient was treated with etoricoxib (90 mg once daily) and etanercept. A splint was applied as conservative therapy. Symptoms stopped after a few weeks.

Case 2. A 77-year-old white woman with a progressive, erosive, rheumatoid factor-positive RA and a mild psoriasis was treated with different doses of MTX for 11 years. Her current medication included pantoprazole $(20 \mathrm{mg}$ once daily), naproxen (500 $\mathrm{mg}$ twice daily), folic acid (5 $\mathrm{mg}$ once weekly), etanercept (50 mg subcutaneously once weekly), leflunomide (10 mg once daily), and MTX (25 mg subcutaneously once weekly). She did not use preventive medication for osteoporosis. In the past she had been treated with low doses of prednisolone for a short duration. Her other medical history included a total hip procedure on both right sides, a femur fracture, and a mild psoriasis. Her body weight was $62 \mathrm{~kg}$ with a height of $155 \mathrm{~cm}$.

Eight years after diagnosis of RA, she presented herself with severe pain in her proximal left tibia that prevented her from walking and was relieved by rest. Physical examination disclosed severe tenderness on the tibia with a mild edema. Radiographs of the knees showed signs of osteoarthritis on both sides without any other pathology. Because of ongoing pain in the left knee, an additional MRI was done. The MRI showed signs of a fracture in the medial side of the proximal tibia with local bone marrow edema (Figure 3). Laboratory tests showed an elevated erythrocyte sedimentation rate (ESR) of $71 \mathrm{~mm} / \mathrm{h}$ and an increased alkaline phosphatase of $133 \mathrm{U} / 1$. DEXA showed osteopenia of the lumbar spine (BMD T score -1.3). A bone biopsy was not taken. MTX therapy was stopped and other medication was continued. A splint was applied as conservative therapy. MTX was restarted after a few weeks because of RA activity. A few months later she died of a nonrelated disease in the intensive care unit.

Case 3. A 68-year-old white man with RA for almost 35 years was treated with different doses of MTX for 9 years. His current medication included MTX (25 mg subcutaneously, once weekly), folic acid (5 mg once week1y), hydroxychloroquine (200 mg once daily), and omeprazole (20 mg once daily). He did not use preventive medication for osteoporosis. His body weight was $86 \mathrm{~kg}$ with a height of $174 \mathrm{~cm}$. His other medical history included a fracture of his right elbow.

After 25 years with RA, radiographs of his hands, feet, shoulders, and knees did not show any abnormalities. Initially, radiographs of the knees 2 months before fracture showed osteoarthritis but a normal calcareous skeleton. At the time of the fracture an MRI was done because of knee pain unrelated to RA. The MRI showed a fracture in the medial side of the proximal tibia (Figure 4). Laboratory tests showed an ESR of $31 \mathrm{~mm} / \mathrm{h}$ and an 


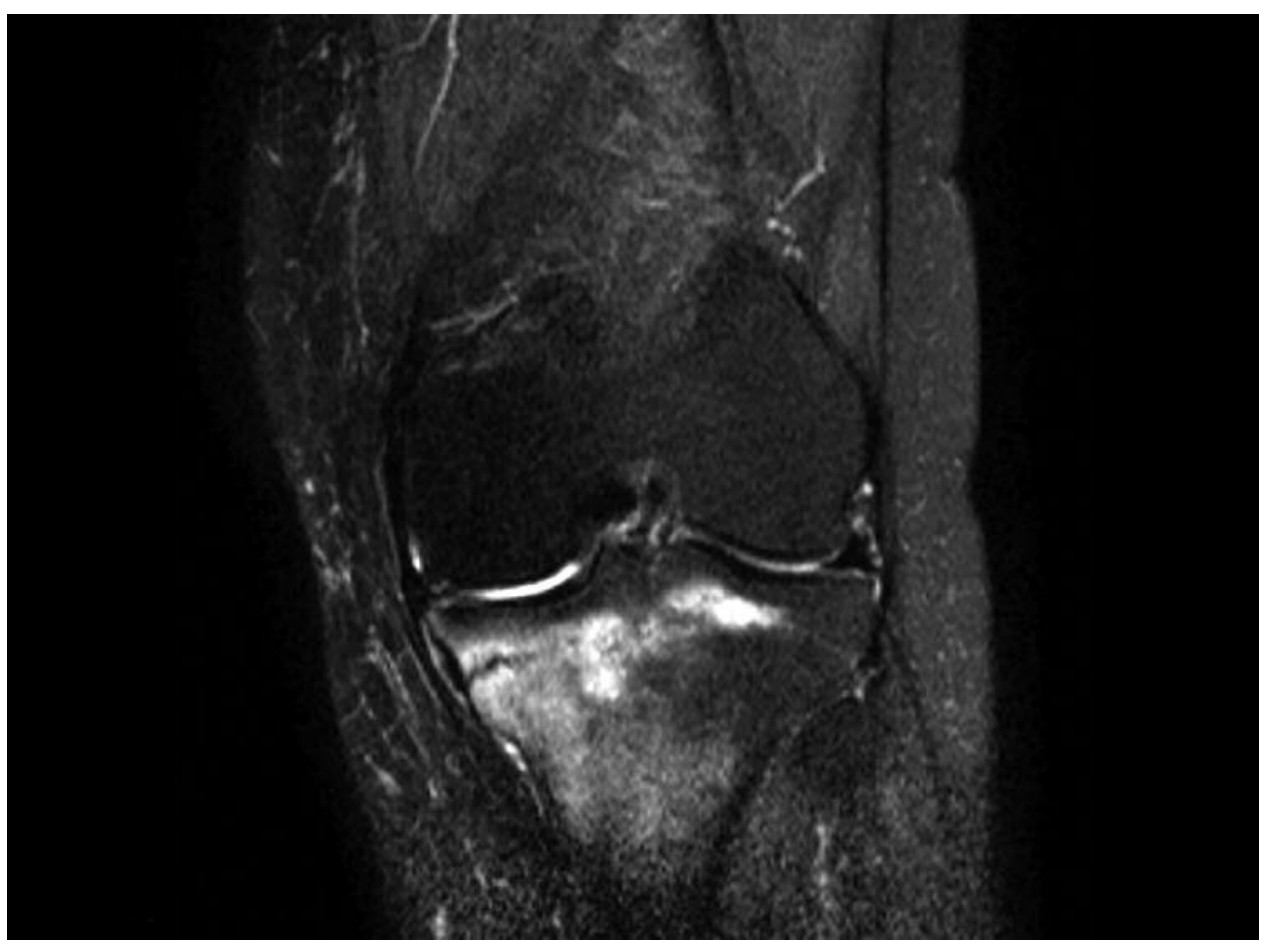

Figure 3. Coronal fat-suppressed T2-weighted magnetic resonance image shows a hypointense transverse fracture of cancellous and cortical bone of the proximal tibial metaphysis. There is associated bone marrow and periosteal edema.

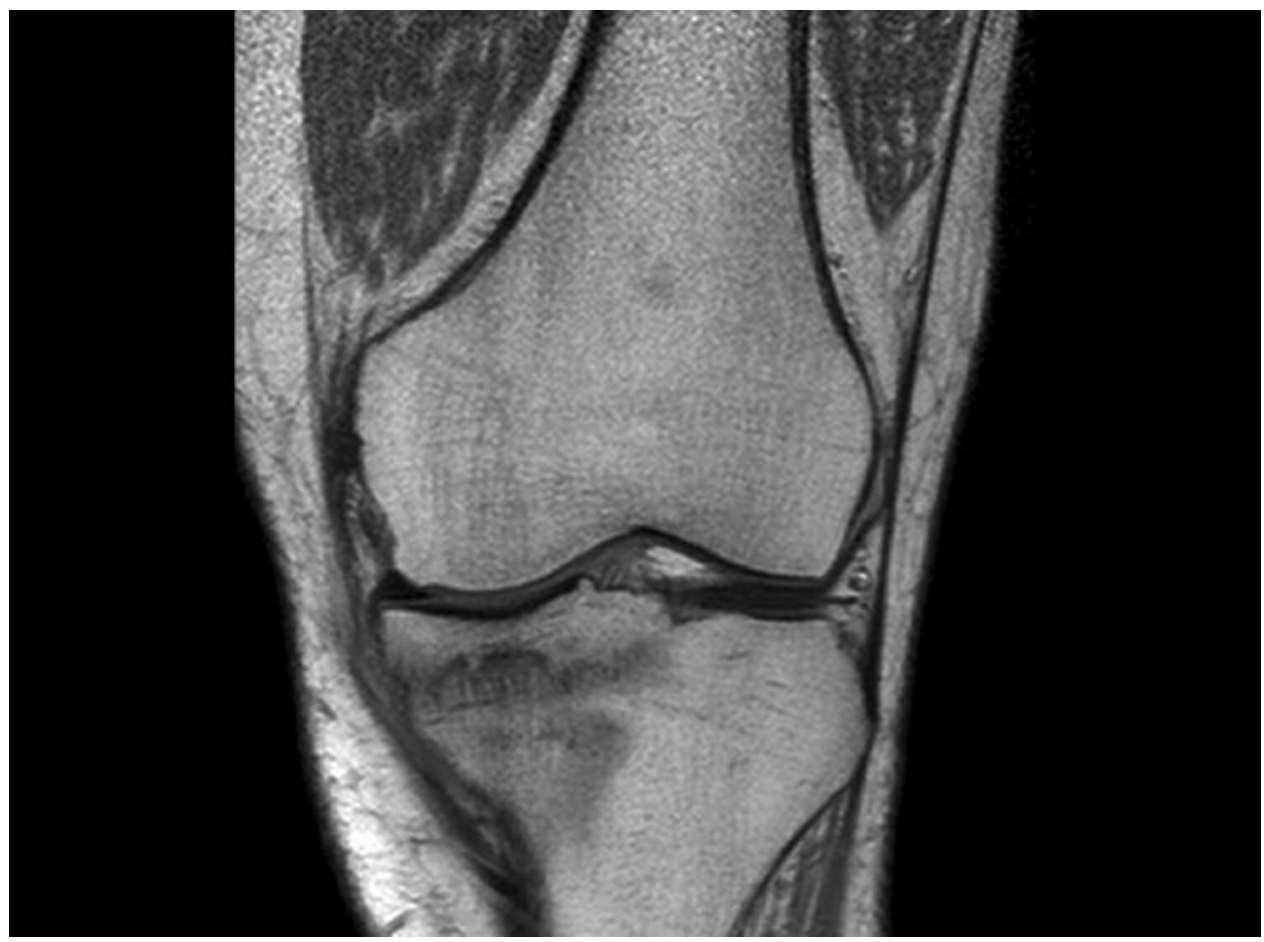

Figure 4. Coronal T1-weighted magnetic resonance image shows a fracture of the medial tibia plateau, not an intraarticular fracture. It is a hypointense transverse fracture of cancellous and cortical bone of the proximal tibial metaphysis. There is associated bone marrow and periosteal edema. 
alkaline phosphatase level of $104 \mathrm{U} / 1$. DEXA of the lumbar spine showed a normal T score (BMD T score +0.3). DEXA of total hip showed osteopenia with a $\mathrm{T}$ score of -2.4 . MTX therapy was stopped, but continued after 3 months because of RA activity. The fracture has healed without residual damage. The patient's pain subsided quickly.

MTX, an antimetabolite, is a folic acid antagonist and in oncology it is usually given orally but also can be given intramuscularly, intravenously, or intrathecally, depending on the type of cancer ${ }^{6}$. MTX competitively inhibits the reduction of tetrahydrofolate by dihydrofolate reductase, thus inhibiting the synthesis of DNA and RNA ${ }^{1}$. The drug is commonly used at high doses (100-1000 mg/m²) in the treatment of lymphoma, lymphoblastic leukemia, and osteosarcoma. In autoimmune diseases, MTX is used at low doses (up to $30 \mathrm{mg}$ once weekly) given orally or by intramuscular or subcutaneous injections ${ }^{7}$. It has antiinflammatory and cytokine-modulating properties that are thought to contribute to the beneficial effect of MTX in the treatment of RA and other chronic inflammatory conditions such as psoriasis and psoriatic arthritis ${ }^{8}$. Complications of MTX, which include hematological and hepatic adverse events and less frequently lung or bone marrow toxicities, are well known and may easily be detected by careful monitoring of hematological measurements and renal and hepatic functions ${ }^{1}$.

The use of high-dose MTX has been associated with osteopathy, characterized by severe bone pain, localized osteoporosis, and even spontaneous insufficiency fractures of the lower extremities ${ }^{3}$. But there also have been reports of fragility fractures (e.g., fractures that result from mechanical forces that would ordinarily not cause fractures and that reflect poor bone quality) occurring in adult patients taking longterm, low to intermediate dosages of MTX for RA, psoriasis, and/or psoriatic arthritis $^{9,10,11,12,13,14}$. MTX can damage bone in 2 ways, possibly leading to osteopathy. Previous studies showed increased urinary and fecal excretion of calcium in MTX use, indicating enhanced osteoclastic bone resorption $^{9,15}$. Other investigations showed that short-term administration of MTX in rats produced toxic effects on osteoblasts, with a $60 \%$ reduction in the rate of bone formation, resulting in decreased osteoid volume and thickness ${ }^{16}$. Reduced bone turnover by these 2 mechanisms could predispose patients to delayed microfracture repair, with osteopathy as a result 9 . Van Leeuwen, et al said that clinical studies with multiagent chemotherapy have demonstrated that antimetabolites decrease bone growth and final height ${ }^{17}$. He also described the effect of MTX on the growth of male Wistar rats. Treatment with MTX reduces the proximal tibial growth plate shear strength because of a decreased surface area and maximum shear stress ${ }^{18}$.

Although the presence of osteopathy in patients with inflammatory conditions treated with longterm and short-term low-dose MTX has been reported, with resolution of the symptoms on withdrawal of MTX, it is still debated ${ }^{19,20}$. Minaur, et al reported results in a prospective nonrandomized trial with 116 non-steroid-treated RA subjects that suggest that MTX is safe for bone health at a low dose (10-15 mg once weekly $)^{7,21}$. A critical review of published reports suggests that most patients treated with low-dose MTX do not have an increased risk of MTX osteopathy ${ }^{22}$. Buckley, et al showed that longterm low-dose administration of MTX does lead to reduced bone density in patients treated with the combination MTX plus prednisolone more than in patients treated with prednisolone alone ${ }^{23}$. Preston, et al reported cases of osteopathy in postmenopausal women taking low-dose MTX, indicating this hormonal status to be of attributional importance?.

Fragility fractures have been reported mainly at the distal tibia site in subjects taking low doses of MTX ${ }^{9,10,11}$. Here we present 3 patients who developed fragility fractures at the proximal tibia site during longterm low-dose to intermediate-dose MTX treatment. To our knowledge this has not been described before. Two patients had been treated with oral glucocorticoids in the past for a maximum of 2 years. The dosage was 5 or 10 $\mathrm{mg}$ once daily. Glucocorticoids are known for damaging bone metabolism. In our patients, glucocorticoid treatment can be ruled out as a possible cause of the fractures. In none of the patients were there signs of osteoporosis. DEXA showed osteopenia in all 3 patients. Osteopathy is a rare and relatively unknown complication during MTX treatment; precise incidence numbers are lacking. Mainly the distal tibia is at risk for fragility fractures during MTX treatment.

BMD measurement showed only osteopenia but bone strength is determined by bone mass, geometry, and quality. The latter includes several aspects of bone structure and composition, including bone turnover, microarchitecture, the degree and distribution of mineralization, the extent of microdamage and its repair, and finally, the composition of bone matrix and mineral ${ }^{24}$. BMD measurement does not show all these components.

We described 3 patients taking longterm low-dose to intermediate-dose MTX therapy with a fracture of the proximal tibia, presumably caused by MTX treatment. It is important to become aware of this side effect in distal as well as proximal tibia as the only therapy is withdrawal of MTX. Therefore we would like to emphasize the importance of keeping osteopathy in mind when patients being treated with longterm low to intermediate MTX complain of knee pain. Further, negative results in knee radiographs do not exclude pathology, and for patients with persistent complaints an MRI should be performed.

LOUISE MEIER, MSc, Department of Rheumatology, Máxima Medical Center Eindhoven; ANNE-MOON van TUYLL van SERSOOSKERKEN, MD, Department of Dermatology, University Hospital Maastricht; ELLEN LIBERTON, MD, Department of Dermatology; LUCAS KLEIJN, MD, Department of Orthopedic Surgery, Elkerliek Hospital Helmond; TOON WESTGEEST, MD, Department of Rheumatology; MARTIN POLAK, MD, Department of Radiology; RON de NIJS, PhD, Department of Rheumatology, Máxima Medical Center Eindhoven, The Netherlands. Address correspondence to L. Meier, Department of Rheumatology, Máxima Medical Center Eindhoven, Postbox 90052, 5600PD Eindhoven, The Netherlands. E-mail: L.Meier@mmc.nl

\section{REFERENCES}

1. Stevens H, Jacobs JW, Van Rijk PP, De Klerk JM. Methotrexate osteopathy demonstrated by technetium-99m HDP bone scintigraphy. Clin Nucl Med 2001;26:389-91.

2. Torikai E, Kageyama Y, Takahashi M, Nagano A. The effect of methotrexate on bone metabolism markers in patients with rheumatoid arthritis. Mod Rheumatol 2006;16:350-4.

3. Ragab AH, Frech RS, Vietti TJ. Osteoporotic fractures secondary to methotrexate therapy of acute leukemia in remission. Cancer 1970;25:580-5.

4. Arend WP, Dayer JM. Inhibition of the production and effects of interleukin-1 and tumor necrosis factor alpha in rheumatoid arthritis. Arthritis Rheum 1995;38:151-60.

5. Maini RN, Taylor PC. Anti-cytokine therapy for rheumatoid arthritis. Annu Rev Med 2000;51:207-29.

6. Robson H, Anderson E, Eden OB, Isaksson O, Shalet S. Chemotherapeutic agents used in the treatment of childhood malignancies have direct effects on growth plate chondrocyte proliferation. J Endocrinol 1998;157:225-35.

7. Minaur NJ, Jefferiss C, Bhalla AK, Beresford JN. Methotrexate in the treatment of rheumatoid arthritis. In vitro effects on cells of the osteoblast lineage. Rheumatology 2002;41:735-40.

8. Constantin A, Loubet-Lescoulie P, Lambert N, Yassine-Diab B, Abbal M, Mazieres B, et al. Anti-inflammatory and immunoregulatory action of methotrexate in the treatment of rheumatoid arthritis: evidence of increased interleukin- 4 and interleukin-10 gene expression demonstrated in vitro by competitive reverse transcriptase-polymerase chain reaction. Arthritis Rheum 1998;41:48-57.

9. Preston SJ, Diamond T, Scott A, Laurent MR. Methotrexate osteopathy in rheumatic disease. Ann Rheum Dis 1993;52:582-5.

10. Shapira D, Scharf Y. Insufficiency fracture of the distal tibia mimicking arthritis in a rheumatoid arthritis patient. The possible role of methotrexate treatment. Clin Exp Rheumatol 1995; 
13:130-1.

11. Maenaut K, Westhovens R, Dequeker J. Methotrexate osteopathy, does it exist? J Rheumatol 1996;23:2156-9.

12. Alonso-Bartolomé P, Martinez-Taboada VM, Blanco R, Rodriguez-Valverde V. Insufficiency fractures of the tibia and fibula. Semin Arthritis Rheum 1999;28:413-20.

13. Wijnands M, Burgers A. Stress fracture in long term methotrexate treatment for psoriatic arthritis. Ann Rheum Dis 2001;60:736-9.

14. Bologna C, Jorgensen C, Sany J. Possible role of methotrexate in the distal tibia fractures in a patient with rheumatoid arthritis. Clin Exp Rheumatol 1996;14:343-4.

15. Nevinny HB, Krent MJ, Moore EW. Metabolic studies on the effects of methotrexate. Metabolism 1965;14:135-40.

16. Friedlaender GE, Tross RB, Doganis AC, Kirkwood JM, Baron R. Effects of chemotherapeutic agents on bone. I. Short-term methotrexate and doxorubicin (adriamycin) treatment in a rat model. J Bone Joint Surgery Am 1984;66:602-7.

17. Van Leeuwen BL, Kamps WA, Jansen HW, Hoekstra HJ. The effect of chemotherapy on the growing skeleton. Cancer Treat Rev 2000;26:363-76.

18. Van Leeuwen BL, Verkerke GJ, Hartel RM, Sluiter WJ, Kamps WA, Jansen HW, et al. Chemotherapy decreases epiphyseal strength and increases bone fracture risk. Clin Orthop Relat Res 2003;413:243-54.
19. Alonso-Bartolomé P, Martinez-Taboada VM, Canga A, Blanco R. Medial tibial stress syndrome due to methotrexate osteopathy. Ann Rheum Dis 2006;65:832-3.

20. Zonneveld IM, Bakker WK, Dijkstra WF, Bos JD, van Soesbergen RM, Dinant HJ. Methotrexate osteopathy in long-term, low-dose methotrexate treatment for psoriasis and rheumatoid arthritis. Arch Dermatol 1996;132:184-7.

21. Minaur NJ, Kounali D, Vedi S, Compston JE, Beresford JN, Bhalla AK. Methotrexate in the treatment of rheumatoid arthritis. II. In vivo effects on bone mineral density. Rheumatology 2002; 41:741-9.

22. Rozin AP. Is methotrexate osteopathy a form of bone idiosyncrasy? Ann Rheum Dis 2003;62:1123.

23. Buckley LM, Leib ES, Cartularo KS, Vacek PM, Cooper SM. Effects of low dose methotrexate on the bone mineral density of patients with rheumatoid arthritis. J Rheumatol 1997;24:1489-94.

24. Compston J. Bone quality: what is it and how is it measured? Arq Bras Endocrinol Metabol 2006;50:579-85.

J Rheumatol 2010;37:11; doi:10.3899/jrheum.100385 